\title{
Turismo de base comunitária e patrimônio cultural imaterial no nordeste brasileiro ${ }^{1}$
}

Community Based Tourism and Intangible Cultural Heritage in Northeast Brazil

Turismo de Base Comunitaria y Patrimonio Cultural Inmaterial en el Noreste de Brasil

http://dx.doi.org/10.18472/cvt.16n3.2016.1168

Cassiana Panissa Gabrielli < cassiana.gabrielli@gmail.com > Universidade Federal de São Carlos (UFSCar), São Carlos, SP, Brasil.

Gabriela Nicolau dos Santos 〈gabrielanicolau.8o@gmail.com > Instituto Federal de Sergipe (IFS), São Cristóvão, SE, Brasil.

1 Este trabalho foi baseado em versões preliminares apresentadas no XI Seminário da Associação Nacional de Pesquisa e Pós-Graduação em Turismo (Anptur), realizado em Fortaleza/CE, em setembro de 2014 e no 5ํㅡㄴ Congresso Latino-Americano de Investigação Turística (Clait), realizado em São Paulo/SP, em setembro de 2012.

CRONOLOGIA DO PROCESSO EDITORIAL

Recebimento do artigo: 14-nov-2015

Aceite: 16-nov-2016

FORMATO PARA CITAÇÃO DESTE ARTIGO

GABRIELLI, C. P.; SANTOS, G. N. dos. Turismo de Base Comunitária e Patrimônio Cultural Imaterial no Nordeste Brasileiro. Caderno Virtual de Turismo. Rio de Janeiro, v. 16, n. 3, p. 141154, dez. 2016.

REALIZAÇÃO

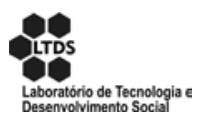

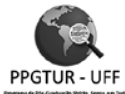

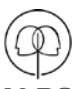

APOIO INSTITUCIONAL

EDIÇÃO

PATROCÍNIO

COPPE

UFR] 


\section{RESUMO}

Este artigo pretende contribuir com a discussão acerca da complexa ligação entre Bens Culturais Imateriais e o Turismo. Para isso, em um primeiro momento, abordaremos a perspectiva da Unesco acerca da aproximação do turismo com o patrimônio cultural imaterial, contrastando-a com análises antropológicas advindas, em grande escala, da Antropologia da Performance (ANDERSON, 1982; SCHECHNER, 1985) e da Antropologia do Turismo (GRUNEWALD, 2003). Em um segundo momento, analisaremos a configuração de alguns roteiros de Turismo de Base Comunitária (TBC) e a utilização, por parte destes, de saberes étnicos circunscritos em modos tradicionais de vida e organização social nos estados do Ceará e Sergipe, na região Nordeste do Brasil. Na última etapa, se detalhará a metodologia adotada pelo Instituto de Pesquisas em Tecnologia e Inovação (IPTI), uma entidade privada sem fins lucrativos, quando da elaboração do Plano de Gestão Participativa do Turismo no município de Santa Luzia do Itanhy (SE), realizado em 2011, com o apoio do Ministério do Turismo. Após o estudo de alguns casos de sucesso e propostas de implantação de TBC, por meio do desenvolvimento de novos modelos de planejamento turístico na região Nordeste do Brasil, foi possível estabelecer a relação direta entre gestão do turismo de base comunitária e seu vínculo com a cultura, a identidade e o patrimônio imaterial.

Palavras-chave: Patrimônio Cultural Imaterial. Antropologia. Turismo de Base Comunitária

\section{ABSTRACT}

This paper aims to contribute to the discussion about the complex link between Intangible Cultural Heritage with tourism. For this, at first, we will address UNESCO's perspective on approach tourism with the intangible cultural heritage contrasting it with anthropological analyzes resulting in large-scale, of Anthropology of Performance (Anderson, 1982; Schechner, 1985) and Tourism Anthropology (Grunewald, 2003). Secondly, we analyze the configuration of some routes of Tourism Community Based (TBC) and uses by those of ethnic knowledge circumscribed in traditional ways of life and social organization in the states of Ceará and Sergipe, in northeastern Brazil. In the last step, we will detail the methodology used by the Institute for Research in Technology and Innovation (IPTI), a private non-profit entity, when preparing the Participative Management Plan for Tourism in the municipality of Santa Luzia do Itanhy (SE), held in 2011, with the support of Ministry of Tourism. After the study of some successful cases and proposals for implementation of TBC by developing new models of tourism planning in the northeastern region of Brazil, it was possible to establish a direct relationship between community-based tourism management and its connection with the culture, identity and the intangible heritage.

Keywords: Intangible Cultural Heritage. Anthropology. Community-Based Tourism.

\section{RESUMEN}

Este artículo tiene como objetivo contribuir a la discusión sobre la compleja relación entre el Patrimonio Cultural Inmaterial con el turismo. Para eso, en un primer momento, se abordará la perspectiva de la UNESCO sobre el enfoque del turismo con el patrimonio cultural inmaterial que contrasta con los análisis antropológicos que resulta en gran escala, de la Antropología de la Performance (Anderson, 1982; Schechner, 1985) y Antropología del Turismo (Grunewald, 2003). En seguida, se analiza la configuración de algunas rutas de Turismo de Base Comunitaria (TBC) y la utilización de los de conocimientos étnicos circunscritos en las formas tradicionales de vida y organización social en los estados de Ceará y Sergipe, en el nordeste de Brazil. En el último paso, vamos a detallar la metodología utilizada por el Instituto de Investigación en Tecnología e Innovación (IPTI), una entidad sin fines de lucro, en la preparación del Plan de Gestión Participativa para el turismo en el municipio de Santa Luzia do Itanhy (SE), que se celebró en 2011, con el apoyo del Ministerio de Turismo. Después del estudio de algunos casos exitosos y propuestas para implementación de TBC mediante el desarrollo de nuevos modelos de planificación del turismo en la región Noreste de Brasil, fue posible establecer una relación directa entre la dirección de turismo de base comunitaria y su conexión con la cultura, identidad y patrimonio inmaterial.

Palabras clave: Patrimonio Cultural Inmaterial. Antropología. Turismo de Base Comunitária. 


\section{Introdução: Turismo e patrimônio cultural imaterial}

Para entender a perspectiva da Unesco com relação à conjugação do Turismo com o Patrimônio Cultural Imaterial (PCI), e sua evolução ao longo do tempo, utilizou-se como referência uma série de apostilas que foram disponibilizadas pelo Centro Regional para a Salvaguarda do Patrimônio Cultural Imaterial da América Latina (Crespial), quando da oferta do Curso Virtual sobre Registro e Inventário do Patrimônio Cultural Imaterial, em 2010.

Primeiramente, se delimitou um conceito pelo que os estudos identificam ser a atividade turística. Para tanto, foi utilizada a definição de Oscar de la Torre (1992), segundo o qual o turismo deve ser compreendido como um fenômeno social que consiste no deslocamento voluntário e temporário de indivíduos ou grupo de pessoas que, fundamentalmente, por motivos de recreação, descanso, cultura ou saúde, saem do seu local de residência habitual para outro, no qual não exercem nenhuma atividade lucrativa nem remunerada, gerando múltiplas inter-relações de importância social, econômica e cultural.

Se para De la Torre (1992) o turismo pode ser entendido como um fenômeno social causado pelo deslocamento das massas, para Fúster (1974), essa mesma atividade envolve também os fenômenos e as relações que esta massa produz em consequência de suas viagens. Para esse autor, além de ser o conjunto das organizações privadas ou públicas que surgem para fomentar a infraestrutura e a expansão do núcleo, as campanhas de propaganda, todo o equipamento receptivo de hotéis, agências de viagens, transportes, espetáculos, guias-intérpretes, o turismo é, também, os efeitos negativos ou positivos que se produzem nas populações receptoras. Assim, é relevante destacar a atividade turística como um fenômeno e analisar as inter-relações sociais, econômicas e culturais - tão intimamente ligadas e difíceis, senão impossíveis, de serem entendidas separadamente - geradas em função do desenvolvimento do turismo em localidades estudadas pelas autoras.

Mário Beni (2004) aponta como efeitos positivos do turismo: o desenvolvimento da criatividade em vários campos; a promoção do sentimento de liberdade mediante a abertura ao mundo; estabelecimento ou extensão de contatos culturais; a promoção da difusão de informações sobre uma determinada região ou localidade, seus valores naturais, culturais e sociais; a integração social e incremento da consciência nacional e a abertura a novas perspectivas sociais como resultado do desenvolvimento econômico e cultural da região.

Entre os efeitos negativos, o citado autor destaca: a degradação e destruição de recursos naturais; mudanças nos padrões de produção e consumo da população local; precariedade na oferta de serviços à parte significativa da população local; desintegração do território / comunidade; dependência do turismo em função da substituição de outras atividades econômicas tradicionais, etc.

Problematizou-se a seguir, sob uma perspectiva antropológica, aspectos referentes ao estabelecimento ou extensão de contatos culturais, as mudanças nos padrões de produção e consumo da população local e a dependência do turismo em função da substituição de outras atividades econômicas tradicionais.

Enquanto objeto de estudo, o tema referente às interações sociais entre turistas e hospedeiros, em comunidades tradicionais, passa a interessar à Antropologia a partir das décadas de 1960 e 1970, em especial a partir da década de 1970 (GRABURN, 2009). Desde então, o interesse crescente por parte dos turistas por sociedades em recônditos da Terra, a procura pelo outro, pelo diferente, pelo exótico (que é buscado desde o início das jornadas turísticas) passou a ser objeto de análise das ciências sociais, assim como os efeitos provocados pelo encontro do turista com o "outro". 
Considerando-se as dinâmicas socioculturais contemporâneas, observa-se que o interesse pela prática turística em comunidades tradicionais tem despertado atenção pelo "exotismo" que caracteriza tais populações ante os turistas oriundos de contextos sociais urbanizados, impregnados de aparatos tecnológicos nas mais diversas esferas de produção e interação sociocultural. Junto a isso, os modos de vida "interioranos", os modos de fazer artesanais, entre outros, têm despertado a atenção não apenas de visitantes, mas também de comunidades que veem no turismo uma oportunidade de dinamizar as relações socioeconômicas locais. Uma das formas de promover tal aproximação, entre visitantes e moradores, mediada pela cultura local, é o Turismo de Base Comunitária (TBC), que será discutido no presente artigo. Sendo o objetivo deste, apresentar discussões teóricas sobre a interação entre turismo de base comunitária e o patrimônio cultural imaterial, além de apresentar alguns exemplos de localidades, situadas no Nordeste brasileiro, onde tais tipos de interação têm sido praticados nos últimos anos.

Nesse modelo de gestão do turismo, o "outro", ou seja, o visitante se desloca com o intuito de conhecer e valorizar a cultura local, especialmente os aspectos relacionados aos bens imateriais desta. A população local, por sua vez, parte da conscientização e valorização de suas identidades culturais para a estrutração democrática das atividades turísticas que envolvem, em geral, modos de "saber fazer" tradicionais. É justamente essa relação dos bens imateriais com o turismo que discutiremos a seguir.

\section{O Patrimônio Cultural Imaterial (PCI) e sua problemática relação com o turismo}

Por Patrimônio Cultural Imaterial entende-se os usos, representações, expressões, conhecimentos e técnicas - com os instrumentos, objetos, artefatos e espaços culturais que lhes são inerentes - que as comunidades, os grupos e, em alguns casos, os indivíduos, reconheçam como parte integrante de seu Patrimônio Cultural. Transmitido de geração em geração, o PCI é recriado constantemente pelas comunidades e grupos em função de seu entorno, sua interação com a natureza e sua história, infundindo um sentimento de identidade e continuidade, contribuindo para promover o respeito à diversidade cultural e à criatividade humana (UNESCO, 2003). ${ }^{2}$

De acordo com a Unesco (2015), o PCI se manifesta em diferentes âmbitos, a saber: tradições e expressões orais; ${ }^{3}$ as artes do espetáculo, representação; ${ }^{4}$ usos sociais, rituais e atos festivos; conhecimentos e usos relacionados com a natureza e o universo e técnicas artesanais tradicionais.

No Brasil, a classificação que foi adotada pelo Instituto do Patrimônio Histórico e Artístico Nacional (Iphan) compartimenta o PCI em quatro livros. O dos Saberes: diz respeito aos conhecimentos e modos de fazer enraizados na vida cotidiana das comunidades; Formas de Expressão: envolve as manifestações literárias, musicais, plásticas, cênicas e lúdicas; Celebrações: inserem-se os rituais e festas que marcam a vivência coletiva do trabalho, da religiosidade, do entretenimento e de outras práticas da vida social e, por fim, o livro dos Lugares: vislumbrando mercados, feiras, santuários, praças e demais espaços onde se concentram e reproduzem práticas culturais coletivas.

De acordo com o conteúdo teórico presente no material fornecido pela Unesco/Crespial quando da oferta do Curso Virtual sobre Registro e Inventário do PCI, uma das principais premissas acerca do PCI diz respeito à noção de que o valor do patrimônio não radica em seu caráter expressivo formal, mas em

\footnotetext{
2 Convenção para a Salvaguarda do Patrimônio Cultural Imaterial, Paris. 3 Incluído o idioma como veículo do patrimônio cultural imaterial.

4 Manifestações coletivas que têm um caráter cênico e se executam para ser mostradas a uma comunidade e à sociedade em geral, mas que ao mesmo tempo dotam de identidade a comunidade ou o grupo ao qual estejam vinculadas.
} 
sua dimensão simbólica. Nesse sentido, constituiriam o sustento e a razão de ser do patrimônio imaterial, conhecimentos e saberes ancestrais, relações sociais, usos e representações simbólicas, toda uma trama complexa de sentidos, de relações sociais e culturais.

Mediante o exposto, observa-se uma eleição clara da Unesco pela perspectiva antropológica de análise do chamado patrimônio cultural. Essa eleição se evidencia igualmente quando adota a pesquisa de campo como método privilegiado para as ações práticas de Registro ${ }^{5}$ dos bens inventariados, que incluem as etapas de levantamento preliminar, identificação e documentação (CASTRO, 2006).

A Unesco ressalta ainda, como características intrínsecas ao Patrimônio Cultural Imaterial, seu aspecto mutante e dinâmico, enfatizando, por isso, ser necessário que se atente aos diferentes fatores de transformação e que se detecte processos de mudança ou alteração, os quais não respondem à dinâmica própria das comunidades ou grupos, mas respondem a agentes externos ou imposições de fora.

Entende-se que o turismo, tal qual figura em grande parte dos textos que abordam sua inserção e expansão em comunidades tradicionais, pode ser compreendido como uma das "formas de imposição desde fora", visto que, em muitas ocasiões, o seu desenvolvimento ocorre à revelia da comunidade local, ou sem considerá-la como parte indispensável do processo de planejamento. Perceber, entretanto, a forma de experiência turística caracterizada pela promoção do outro, nos parece de extrema relevância na medida em que se tem configurado não apenas como alternativa econômica valiosa para as comunidades turísticas, mas para a própria revitalização cultural de manifestações esquecidas ou adormecidas.

Antes de entrar no âmago dessa discussão, é plausível analisar alguns extratos encontrados no material ofertado no Curso Virtual sobre Registro e Inventário do Patrimônio Cultural Imaterial. A princípio, mais especificamente na década de 1970, como expôs a Convenção sobre Proteção do Patrimônio Mundial, Cultural e Natural, que ocorreu em Paris de 17 a 21 de novembro de 1972, reforçou as políticas de conservação do patrimônio e se converteu na norma de referência obrigatória para incluir as políticas de conservação - o turismo era visto como um instrumento de desenvolvimento e sua conjugação com o patrimônio cultural parecia ser vista ainda com bons olhos. ${ }^{6}$

O crescimento do turismo nas décadas seguintes e a incorporação de manifestações tradicionais diversas nos roteiros turísticos, no entanto, geraram um aparente receio por parte da Unesco (2010), como se verifica no extrato abaixo:

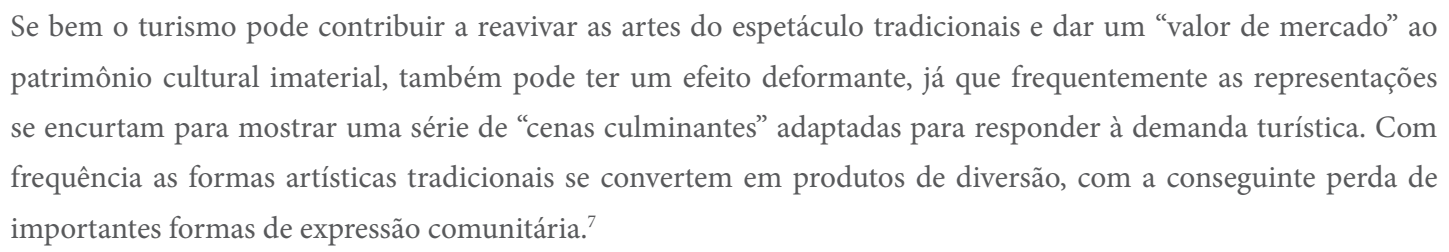

Em que medida a adaptação de formas artísticas tradicionais para o consumo turístico implica em perda de importantes formas de expressão comunitária? Em todos os lugares em que o turismo se apresente, o risco seria o mesmo para cada manifestação encontrada pela massa? O que a Unesco entende como "efeito deformante", aparentemente, encontra paralelo com o que alguns autores da literatura sobre Antropologia

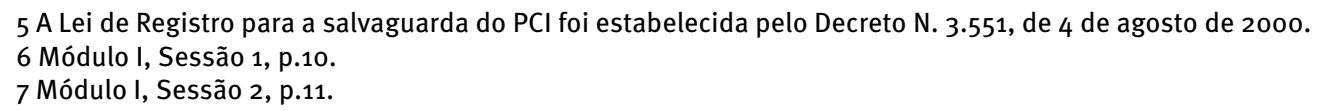


do Turismo ${ }^{8}$ chamam de "teatralização da cultura", artifício não necessariamente recriminável, uma vez que, contemporaneamente, diversos agentes sociais se utilizam do turismo para sua sobrevivência, ou para a sobrevivência de sua renovada forma de expressão.

No extrato a seguir percebemos a "importância" do turismo a partir de seu viés econômico ou a inestimável "ajuda financeira” oferecida pelos visitantes aos organizadores de festas e bailes populares:

\begin{abstract}
Muitas comunidades registraram uma participação crescente de turistas em seus acontecimentos festivos e, ainda que essa participação possa ter aspectos positivos, as festividades sofrem muitas vezes as mesmas consequências que as artes tradicionais do espetáculo. A viabilidade dos usos sociais e os rituais, e em particular dos acontecimentos festivos, pode depender também do contexto socioeconômico geral. Os preparativos, a elaboração de fantasias e máscaras e os gastos com os participantes costumam ser muito caros, e em momentos de crises econômicas nem sempre podem ser custeados. ${ }^{9}$
\end{abstract}

Verificou-se que em grande parte da literatura acerca do tema em questão encontra-se, por parte dos autores, uma visão negativa sobre as transformações ocorridas em manifestações locais em função de sua exploração ou utilização pelo turismo. De acordo com essa perspectiva, o desenvolvimento turístico levaria os nativos de pequenas cidades hospedeiras a abandonarem um modo de vida tradicional e independente do capitalismo global para inserir-se em negócios locais incrementados pelo turismo. Sem negar a importância desses estudos para a construção de um olhar crítico acerca do fenômeno turístico em toda sua complexidade, Grunewald (2003) destaca uma "perspectiva mais produtiva" que reforça a etnicidade promovida entre certas populações como um reforço de certas tradições que passaram à condição de chamariz turístico, participando da perspectiva do desenvolvimento local do turismo. No entanto, "alentar-se-á todas as partes a zelar especialmente para que as atividades de sensibilização não tenham como consequência [...] fomentar uma comercialização excessiva ou um turismo não sustentável, que poderia pôr em perigo o devido patrimônio cultural" (UNESCO, 2010, p. 11-12). Mais uma vez, em meio a outros fenômenos ou "efeitos da mundialização", como as emigrações, o desenvolvimento do individualismo, a generalização da educação formal, a influência crescente das grandes religiões mundiais, o turismo é destacado.

Note-se que ao mesmo tempo em que valoriza e enfatiza a dinamicidade do patrimônio e sua ressignificação, a Unesco se mostra conservadora em perceber ou admitir que as mudanças de significado sofridas por algumas manifestações tradicionais em lugares específicos podem ter surtido efeitos positivos, ao menos em uma parte dos atores sociais envolvidos com tais práticas.

Não se percebe no discurso oficial da organização, igualmente, nenhuma menção à etnicidade como lugar ou espaço necessário a partir do qual as pessoas falam (GRUNEWALD, 2003). De forma semelhante, passam ao largo do conteúdo teórico dos textos oferecidos no curso, perspectivas oriundas dos estudos culturais como os de Stuart Hall (2004) acerca das identidades fragmentárias, que emergem com segmentações internas, não conseguindo operar como totalidades. Em nenhum momento as transformações vivenciadas pelas manifestações tradicionais são pensadas como novas etnicidades em comunidades com posições subalternas que tentam expor a si mesmas contra o mundo formalizado por forças globalizadas e presentes no prisma do mundo pós-moderno (HALL, 2004).

Ao mesmo tempo em que privilegia o método antropológico em todas as etapas do Registro (inventário e documentação), a organização ignora algumas das premissas básicas da Antropologia da Performance, encabeçada por autores como Victor Turner (1988) e Richard Schechner (1985), que, igualmente, iden-

8 Grunewald (2003) e Yázigi (2009).

9 Módulo I, Sessão 2, p.15. 
tificam: audiências turísticas estão modificando performances em todos os lugares do mundo. A pergunta mais apropriada a ser feita diante do exposto nos parece ser: Como? De forma bastante simplificada, os antropólogos que se dedicaram a estudar eventos performáticos em todo o mundo atribuem as mudanças sofridas pelas performances à mudança na audiência, e problematizam: $\mathrm{O}$ que acontece quando performances são apresentadas para uma audiência que não sabe nada do contexto social e religioso que está vendo? Segundo entendem-se, as respostas podem ser tão variadas quanto o contexto específico em que cada uma delas se desenrola. Daí a importância de que cada caso seja estudado levando em consideração o contexto histórico, social, político e econômico local, assim como os diferentes graus de interação com o turista.

Podemos usar como exemplo o competente trabalho realizado por Michelle Anderson (1982) no Haiti. Ao estudar o voodoo naquele país, ${ }^{10}$ a antropóloga percebeu que, em resposta ao interesse turístico pela manifestação religiosa local, a comunidade havia adaptado o ritual original que, se mantendo o mesmo, era apresentado em três formas distintas: Mariani, Jacmel e Nansoucri. Anderson constatou que a primeira forma, teatral/comercial, observada em Porto Príncipe, onde o fluxo de turistas é alto, era apresentada "apenas" para turista. A segunda forma, social/teatral, foi observada em Jacmel, uma cidade pequena no sul do país, onde o fluxo turístico havia apresentado um boom recente, tinha um caráter mais comercial e era apresentada tanto para haitianos quanto para os turistas. Já a terceira forma, entendida pela pesquisadora como ritual/social, se desenvolvia em uma cidade onde o fluxo turístico era quase inexistente, e era apresentada "apenas" para haitianos.

Anderson (1982, p. 51) concluiu que as três formas, tomadas juntas, compunham o autêntico vudu: "o que faz estas mudanças e o que mantém o $v u d u$ 'vivo' é a audiência cambiante". "E é o que pode vir a matá-lo também", acrescenta Schechner (1985, p. 32), que reconhece o fato de que pode haver mais mudança do que pode absorver um gênero antes que deixe de ser ele mesmo.

Cabe aqui alinhar o que pontuam os autores acima - Schechner e Anderson - com o que Grunewald (2003) descortina: quando uma etnicidade se alavanca em face do turismo, isso não quer dizer que os limites da comunidade sejam coincidentes com os da arena turística. Ou seja, nem todos os nativos estão engajados na etnicidade para o turismo. Na visão do autor anteriormente citado, os que estão, acabam formando outra comunidade: a turística. Constituída e apresentando linhas étnicas, essa comunidade pode ser chamada de etnoturística.

São as nuances particulares de cada encontro entre o turismo e as manifestações culturais e tradicionais locais que deveriam importar aos antropólogos interessados em estudar o fenômeno turístico em sua complexidade. Em cada local em que o turismo se configurar como uma realidade social e oportunidade econômica será necessário entender como a comunidade participa, de maneira diferenciada, do processo. Além disso, e talvez ainda mais importante, seja a compreensão de que a seu modo, e em cada local de maneira diferenciada, os agentes culturais tradicionais negociarão com o turismo e turistas o que poderá ou não ser compartilhado de seu acervo cultural, em que momento e a que preço.

Veremos a seguir como as identidades étnicas, ou não, vêm se apropriando do turismo no Brasil, de forma a favorecer interesses sociais, em uma perspectiva de inclusão, associativismo e desenvolvimento sustentável, dialogando com o patrimônio cultural imaterial de tais comunidades.

10 Principal religião do Haiti, o Voodoo, Vodu ou Vudu teve origem na África e foi trazido pelos escravos que vieram para a América, na época da colonização. 


\section{O Turismo de Base Comunitária (TBC) e os Roteiros Cearenses}

De maneira geral, o turismo comunitário pode ser entendido como uma atividade turística que apresenta gestão coletiva liderada pela comunidade, transparência no uso e destinação dos recursos e na qual a principal atração turística é o modo de vida da população local. Nesse tipo de turismo, geralmente, a comunidade é proprietária dos empreendimentos turísticos e há a preocupação em minimizar o impacto ambiental e fortalecer ações de conservação da natureza.

Segundo Maldonado (2009, p. 31), especialista da Organização Internacional do Trabalho e coordenador da Rede de Turismo Sustentável da América Latina (RedTurs),

Por Turismo Comunitário entende-se toda forma de organização empresarial sustentada na propriedade e na autogestão sustentável dos recursos patrimoniais comunitários, de acordo com as práticas de cooperação e equidade no trabalho e na distribuição dos benefícios gerados pela prestação dos serviços turísticos. A característica distinta do turismo comunitário é sua dimensão humana e cultural, vale dizer antropológica, com objetivo de incentivar o diálogo entre iguais e encontros interculturais de qualidade com os visitantes, na perspectiva de conhecer e aprender com seus respectivos modos de vida.

Segundo o Ministério do Turismo brasileiro (2007), as experiências de Turismo de Base Comunitária no país datam de meados dos anos 1990, e foram organizadas independentemente de ações públicas. Com a criação do Ministério do Turismo, em 2003, as iniciativas de TBC são reconhecidas pelo órgão como um fenômeno social e econômico em algumas regiões do território nacional, por meio de organizações não governamentais e pesquisadores do tema, como porta-vozes dessas iniciativas.

Nos anos de 2006 e 2007, tanto representantes das iniciativas de TBC, como pesquisadores do tema, demandaram do poder público uma ação mais articulada, com o reconhecimento do Turismo de Base Comunitária. A intensificação do diálogo entre órgãos do governo federal, academia e iniciativas de TBC resultou na decisão de apoiar o desenvolvimento da atividade no país por meio de um processo seletivo de projetos via Edital de Chamada Pública. Este foi lançado em 2008, com o objetivo de conhecer e apoiar o desenvolvimento das iniciativas com esse perfil em todo o Brasil.

Essa decisão, do ponto de vista da oferta, considerou a expansão de bens e serviços e a gestão da atividade turística nos territórios, sob a responsabilidade das comunidades locais. Do lado da demanda, pesquisas nacionais e internacionais apontavam o interesse crescente dos turistas pela vivência de experiências, convívio com culturas diferentes, ambientes preservados, crescente segmentação e fragmentação das viagens, que indicavam para a potencialidade das iniciativas de TBC no país.

Por meio do edital, 50 projetos distribuídos em 19 estados brasileiros foram aprovados, embora nem todos tenham sido executados. O Projeto da Rede Tucum foi um deles, pioneiro na área de turismo comunitário no Ceará. Abrangendo diversas comunidades do estado, que se localiza no nordeste do Brasil, a Rede oferece para os mercados nacional e internacional um produto turístico projetado para a interação entre povos distintos, atento a proteger e valorizar culturas e territórios, economicamente integrados às atividades tradicionais e com a finalidade de produzir recorrentes benefícios a toda a comunidade.

Atualmente, a Tucum conta com a participação de dez comunidades costeiras, entre indígenas, pescadores e moradores de assentamentos rurais, dois pontos de hospedagem solidária em Fortaleza, além de duas ONGs que fazem o apoio institucional à rede - Instituto Terramar (Brasil) e Associação Tremembé (Itália). 
A Rede busca o fortalecimento da proposta de turismo comunitário, oferecendo belas paisagens aliadas ao compromisso social. Juntas, cada comunidade se fortalece, fomentando a troca de experiências e a cooperação, tendo em vista o compartilhamento de saberes e a construção de estratégias coletivas de superação dos desafios a serem enfrentados. Lembrando que o TBC se diferencia justamente por ser

[...] uma oportunidade para as populações locais possuírem o controle efetivo sobre o seu desenvolvimento, sendo diretamente responsáveis pelo planejamento e gestão das atividades, das estruturas e dos serviços turísticos propostos. [...] dialogando com os princípios que orientam e fortalecem relações solidárias entre homens e mulheres construtores/as de uma sociedade comprometida com a sustentabilidade em seus aspectos políticos, socioculturais, ambientais e econômicos (BRASIL, 2010, p. 8).

Interessa-nos, neste momento, destacar a relevância que a etnicidade assume nos roteiros da Rede Tucum, assim como o protagonismo que, de certo modo, é dado às minorias e causas sociais diversas no desenvolvimento dos produtos turísticos. No material utilizado para levantamento de dados referentes aos destinos oferecidos pela Rede Tucum, ${ }^{11}$ sobressaem-se os termos exploração, resistência, luta e desigualdade. O que pretendemos nesta última etapa do artigo é apresentar casos concretos em que o turismo, diferentemente do que geralmente se destaca no material acadêmico sobre o tema, tem sido desenvolvido conscientemente por comunidades que se apropriam e valorizam aspectos étnicos e identitários para compartilhá-los com seus visitantes.

Para além da preocupação com o bem-estar do turista e oferta de cenários paradisíacos - já amplamente conhecidos e comercializados aos turistas internacionais -, no Ceará, em cada roteiro comercializado pela Tucum, uma luta, uma vitória, um conflito se descortinam, transformando-se em repertório a ser defendido, lembrado e contado aos visitantes.

Em Ponta Grossa, um dos destinos de TBC do Ceará, por exemplo, conta-se que o direito de permanecer na terra foi conquistado ainda nos anos 1990 e que a venda das propriedades ali é terminantemente proibida, revelando uma importante luta travada entre a reforma agrária e as atividades econômicas ligadas à especulação imobiliária e à carcinicultura.

Em Tremembé, outro destino cearense, os serviços turísticos são gerenciados por uma ONG que utiliza a renda gerada com a pousada no fomento de projetos sociais na região. No assentamento Coqueirinho, hortas orgânicas, sistemas agroflorestais, apiário e bancos de sementes são atrativos turísticos. Em quase todas as comunidades a história se repete: conquista de reservas extrativistas, criação de cooperativas, utilização do meio tradicional de vida como principal atrativo, pesca artesanal, agricultura familiar, artesanato e folclore.

É interessante, ainda, apresentar a experiência de turismo comunitário realizada em Nova Olinda, na região do Cariri cearense. Diferentemente das demais comunidades, relacionadas à rede Tucum, Nova Olinda se localiza no sertão semiárido, em uma localidade até então pouco explorada turisticamente. Lá, o TBC surgiu pela necessidade de se operacionalizar o receptivo turístico no município que passou a receber muitos visitantes por conta das atividades desenvolvidas pela Fundação Casa Grande - Memorial do Homem Kariri (FCG/MHK) e pelo interesse científico pelos geossítios lá presentes.

Fundada com o intuito de valorizar e preservar o patrimônio cultural e geológico local, por meio de formação social e cultural de jovens e crianças da comunidade, na FCG/MHK são oferecidos diversos cursos e atividades contando com oficinas técnicas, laboratórios, bibliotecas, teatro, além do Museu do

11 Série Turisol de metodologias. Turismo comunitário rede cearense de turismo comunitário. Tucum. 
Homem Kariri e da rádio comunitária Casa Grande. Fundamentada em um modelo de gestão participativo diferenciado, no qual as crianças são as coordenadoras de toda a estrutura da fundação, a ONG passou a atrair diversos visitantes e parceiros. Esses, quando em visita ao município, tinham que se hospedar em cidades vizinhas, pois não havia meios de hospedagem na localidade.

Desse modo, iniciou-se a oferta de hospedagem nas casas dos pais das crianças que frequentam a Fundação. No intuito de aproximar ainda mais a comunidade, os pais foram convidados também a gerirem o refeitório da FCG/MHK, produzindo e comercializando refeições e lanches para os visitantes e também a produzirem artefatos artesanais para serem vendidos na loja lá encontrada.

Desde 2010, um dos "meninos" da Fundação criou e gerencia a Agência de Turismo Comunitário Fundação Casa Grande, que oferece serviços como marcação de passagens, transfer rodoviário, roteiros e passeios por toda a região, além de hospedagem domiciliar. Após a consolidação da estrutura receptiva, egressos da fundação organizaram roteiros na cidade que priorizam visitas a oficinas de artesãos que trabalham com couro, pedra cariri, renda, entre outros. Na área rural o destaque é a propriedade de Seu Zé Arthur, na qual se desenvolve a técnica de agrofloresta, tendo uma flora, atualmente, totalmente diferenciada das demais da região, e sendo também uma das casas a ofertar hospedagem domiciliar na zona rural.

O saber e o fazer se sobrepõem como atrativos aos próprios materiais produzidos na localidade. A Fundação Casa Grande se tornou uma referência atraindo visitantes de diversas cidades do Brasil e do mundo, estando diretamente relacionada à valorização dos saberes e fazeres locais, possibilitando a inserção de diversos agentes beneficiários na cadeia produtiva do turismo. Esse projeto tem sido desenvolvido por iniciativa particular, contando com apoio de editais públicos e privados, além de doações, apoios e patrocínios para projetos específicos.

Em meio a municípios com vocações turísticas diferenciadas, especialmente o turismo religioso em Juazeiro do Norte e Crato; o turismo científico em Santana do Cariri e o turismo cultural em Barbalha, Nova Olinda se destacou, sendo inclusive escolhida como destino indutor do turismo na região pelo MTUR, justamente por conta do trabalho relacionado ao turismo de base comunitária que lá tem sido desenvolvido.

\section{Metodologia de Implantação do Turismo de Base Comunitária no Estado de Sergipe}

Finalmente, abordaremos a experiência de implantação do Turismo de Base Comunitária no estado de Sergipe, que aconteceu entre os meses de fevereiro e dezembro de 2011, em dois municípios situados no litoral sul de Sergipe: Santa Luzia do Itanhy e Estância.

De maneira semelhante ao projeto da Rede Tucum, a experiência em Sergipe aconteceu graças ao convênio firmado, em 2010, entre o Ministério do Turismo e o Instituto de Pesquisas em Tecnologia e Inovação (Ipti), uma entidade privada sem fins lucrativos, em parceria com a Secretaria de Turismo do Estado de Sergipe. Nessa ocasião, foi proposto ao Ministério a elaboração do chamado Plano de Gestão Participativa do Turismo do Município de Santa Luzia do Itanhy.

Inicialmente, utilizou-se como metodologia a pesquisa bibliográfica e o trabalho de campo. As visitas in loco realizadas ao longo de uma semana foram utilizadas como método para entender aspectos da dinâmica local do município de Santa Luzia do Itanhy. Com o suporte do material bibliográfico foram identificados 14 coletivos, que configuraram a chamada "rede de agentes beneficiários do plano". Entre estes se encontravam pescadores; agricultores; líderes comunitários; assentados rurais; chefes e integrantes de 
grupos artísticos (Reisado e Samba de Coco); Associação das Mulheres; Sindicato de professores; agentes do poder público; agentes de saúde; proprietários de fazendas históricas; líderes religiosos; representantes/ líderes dos povoados mais distantes da sede; representantes da Reserva Ambiental da Mata do Crasto e representantes do trade (donos de restaurante, meios de transporte e meios de hospedagem).

Como meio de aproximação dos coletivos identificados, foi elaborado um questionário que buscava identificar, entre outros aspectos, a qualidade de vida dos agentes; as atividades desenvolvidas por esses agentes; aspectos positivos e negativos do local onde viviam; o que eles consideravam ser importante para a cultura local, portanto, patrimônio cultural; a ideia que possuíam acerca do cooperativismo e de sua importância; sugestões para melhorar as condições em que viviam; abertura e predisposição para trabalhar com o turismo e, finalmente, o grau de interesse em participar das oficinas e a disponibilidade de tempo para frequentá-las. O questionário serviu de suporte para a realização de 31 entrevistas semidirigidas direcionadas a dois membros de cada um dos coletivos acima mencionados.

Aproveitando a oportunidade de contato com esses atores, a cada entrevistado era entregue um convite com informações básicas acerca das oficinas de sensibilização e mobilização que seriam realizadas na etapa seguinte, com uma breve descrição do conteúdo programático, datas, horário e o local de realização. Como parte da metodologia desenvolvida para a etapa inicial, uma câmera fotográfica descartável foi entregue a cada entrevistado, ao qual se solicitava que fotografasse três coisas "boas" e três coisas "ruins" de seu dia a dia. As câmeras fotográficas foram recolhidas pela equipe poucos dias depois. Após reveladas, as fotografias foram utilizadas na oficina em uma dinâmica que pretendia diagnosticar os principais pontos fortes e fracos existentes na região (culinária, danças e folguedos, arquitetura colonial e religiosa, embarcações, etc.) e que, possivelmente, exerceriam influências diretas ou indiretas no desenvolvimento do turismo na localidade.

Uma vez analisados os dados levantados nesta primeira etapa, teve início o processo de elaboração dos conteúdos técnicos para as oficinas, que ocorreram ao longo do mês de abril de 2011. O conteúdo técnico obedeceu aos temas propostos no Termo de Referência: turismo e desenvolvimento local; turismo de base comunitária; programas e projetos de turismo (nacional e estadual) relacionados à região turística do projeto; governança no turismo local; iniciativas de sucesso no desenvolvimento turístico local (participativo, cooperado) e organização local para o desenvolvimento turístico.

Após as oficinas, teve início a etapa de diagnósticos participativos e workshops de roteirização. A metodologia utilizada incluiu visitas, análise e avaliação dos principais pontos turísticos levantados na oficina por parte dos beneficiários do projeto na etapa de sensibilização e mobilização. A participação da comunidade local nos workshops de roteirização era gratuita e não houve nenhum tipo de restrição à entrada de interessados.

De forma geral, o público, composto por aproximadamente 20 pessoas, era formado por agricultores familiares, pescadores, donos de restaurantes, artesãos, gestores públicos e líderes comunitários em geral. Ao todo, foram destacados 15 atrativos no município de Santa Luzia do Itanhy, que se encontravam distribuídos por quatro povoados distintos.

A ideia dos diagnósticos participativos, alicerçada na visita a cada um dos atrativos levantados pela comunidade com os participantes das oficinas de sensibilização e mobilização, adveio da metodologia suge- 
rida por Thaise Guzzatti, que foi uma das idealizadoras do Projeto Acolhida na Colônia, no Sul do Brasil. ${ }^{12}$ No caso desse projeto, que serviu como referência e inspiração para a implantação das etapas iniciais do Plano de Gestão Participativa do Turismo do município de Santa Luzia do Itanhy, cada empreendimento (pousadas domiciliares e restaurantes) era visitado e avaliado pelos próprios participantes ou beneficiários, que assim começavam a vislumbrar as necessidades de aperfeiçoamento dos serviços prestados.

Para a execução da etapa dos workshops de roteirização utilizou-se também a ficha de Avaliação e Hierarquização de Atrativos Turísticos, metodologia sugerida no Módulo Operacional 7 (Programa de Regionalização do Turismo do Ministério do Turismo). A ficha classifica os atrativos em naturais, culturais, atividades econômicas, realizações técnicas, científicas e artísticas e eventos programados. Por meio dela é possível analisar critérios indispensáveis à roteirização, ligados a cada atrativo, separadamente, tais como: grau de atratividade, acesso, infraestrutura, representatividade, interesse comunitário e estado da paisagem circundante. Levando em consideração essa metodologia, as fichas eram preenchidas conjuntamente pelos agentes beneficiários. A última etapa consistiu em inserir no roteiro apenas os atrativos que obtiveram as maiores notas atribuídas pelos participantes dos workshops. Tratavam-se, em geral, de atrativos que reuniam condições de ser visitados imediatamente e/ou em um curto prazo de tempo, tendo em vista um valor baixo e/ou médio de investimento.

Após a sistematização de todas as informações referentes a cada atrativo visitado e avaliado, adotou-se a Análise Swot (metodologia que observa forças e oportunidades, fraquezas e ameaças). Esse procedimento levou à elaboração de um plano de ações que destacou as iniciativas que deveriam ser tomadas em curto, médio e longo prazo, visando à regulamentação e qualificação dos serviços, equipamentos, mão de obra e infraestrutura que compunham o roteiro elaborado. Finalmente, o Plano Estratégico, entendido como a compilação e sistematização de todas as fases do projeto, resultou em um relatório final, entregue ao Ministério do Turismo.

Desse modo, destacamos o caráter participativo, inerente aos princípios do turismo de base comunitária, não apenas no processo de operacionalização, ou gestão dentro da própria comunidade, mas, também, a importância de se considerar e tratar como relevante a participação dos atores locais nas etapas do planejamento de planos e projetos turísticos, oriundos de todas as esferas que venham a intervir na localidade.

\section{Considerações finais}

Como pudemos vislumbrar ao longo das discussões aqui propostas, o turismo diante de uma perspectiva antropológica, por algum tempo foi visto como um elemento de descaracterização de manifestações culturais, especialmente aquelas tradicionais que, ao se popularizarem e serem encenadas em um contexto turístico, foram perdendo, em alguns casos, seus elementos identitários mais representativos. Porém, por meio do desenvolvimento de novos modelos de planejamento turístico, como as iniciativas de turismo de base comunitária, por exemplo, foi possível estabelecer novas relações entre cultura, especialmente relacionada ao patrimônio imaterial, e o turismo.

12 A Associação Acolhida na Colônia originou-se a partir do modelo Accueil Paysan, surgido no sul da Franca nos anos 1980, na região de Grenoble. No Brasil, a experiência de desenvolvimento do agroturismo iniciou-se em 1999, nas encostas da Serra Geral (Santa Catarina). 
Como exemplos, trouxemos alguns casos de TBC desenvolvidos no estado do Ceará, através da rede Tucum, em que a articulação da população é tomada como essencial e representativa da cultura local, visando a manutenção dos seus territórios ante a assédios e especulações de diversos tipos. Além disso, grande parte de tais comunidades se situa em locais de grande beleza cênica do litoral cearense.

Para além das experiências desenvolvidas em redes de cooperação entre comunidades com potencial ou que já desenvolvem o TBC de modo consolidado, existem outras comunidades que têm trabalhado para a articulação do Turismo de Base Comunitária baseado em seu patrimônio cultural imaterial partindo de iniciativas particulares. No Ceará, como vimos, tem-se a experiência da Fundação Casa Grande, que tem levado milhares de turistas por ano para a comunidade, contando com oferta de meios de hospedagem na área urbana do município e também na área rural. Fugindo, de certo modo, da relação com paisagens litorâneas paradisíacas, Nova Olinda se destaca pelo modo de viver da comunidade, assim como pelas ações da ONG FCG/MHK. Nesse contexto, o que se pôde observar é que, diferentemente de muitos destinos turísticos nacionais, lá o turismo serviu como um instrumento de apoio à valorização da cultura e das identidades culturais locais, sendo positiva sua contribuição para a manutenção do patrimônio cultural imaterial local.

Além disso, na última seção do artigo, apresentamos a metodologia de planejamento turístico de Santa Luzia do Itanhy e Estância, localizadas em Sergipe. Tal descrição foi feita com a finalidade de ilustrar não apenas como foi desenvolvido, mas, sobretudo, a importância da participação da população local ao longo de todo esse procedimento a fim de contemplar, durante o processo de desenvolvimento, a importância (tanto da conservação quanto da dinamização) do patrimônio cultural imaterial da comunidade junto às atividades.

Os exemplos da forma como o TBC tem sido planejado e desenvolvido nos estados do Ceará e de Sergipe, no Nordeste brasileiro, visam demonstrar como a cultura, por meio do patrimônio imaterial, pode ser utilizada como um recurso turístico sustentável, possibilitando a integração de diversos setores da sociedade na atividade turística. E essa, por sua vez, pode, e deve, ser um agente ativo no processo de valorização das identidades culturais.

O apoio do governo, em diversas esferas, seja federal, estadual ou municipal, é, sem dúvida, necessário para que o turismo possa atingir sua plena capacidade de desenvolvimento e integração com a comunidade local. Porém, como é sabido, há limitações tanto de ações quanto de financiamentos públicos. Desse modo, iniciativas particulares também podem ser incentivadas, lembrando sempre que não devem, em nenhuma hipótese, serem tomadas como única alternativa ao desenvolvimento local. Tampouco devem ser restritas a pequenos grupos, lembrando que o ideal do turismo de base comunitária é seu caráter democrático e participativo.

\section{Referências}

ANDERSON, M. Authentic Voodoo is Synthetic. The Drama Review. In: TDR, v. 26, n. 2, Intercultural Performance, Summer, 1982. p. 89-110.

BENI, M. C. Análise estrutural do turismo. São Paulo: Senac, 2004. 
BRASIL. Ministério do Turismo. Plano Nacional de Turismo 2007-2010: uma viagem de inclusão. Brasília: Ministério do Turismo, 2007.

CASTRO, M. L. V. de. Patrimônio imaterial no Brasil: legislação e políticas estaduais. Brasília: Unesco, Educarte, 2008.

DE LA TORRE, O. El turismo, fenómeno social. México: Fondo de Cultura Económica, 1992.

FERNÁNDEZ FÚSTER, L. Teoría y técnica del turismo, v. I e II. Madrid: Nacional, 1974.

GRABURN, N. Antropologia ou Antropologias do Turismo? In: GRABURN, N. etal. Turismo e antropologia: novas abordagens. Campinas: Papirus, 2009.

GRÜNEWALD, R. de A. Turismo e Etnicidade. Horizontes Antropológicos, ano 9, n. 20, Porto Alegre: 2003. p. 141-159.

HALL, S. A identidade cultural na pós-modernidade. Rio de Janeiro: DP\&A, 2004.

MALDONADO, C. O Turismo rural comunitário na América Latina. In: BARTHOLO, R. SANSOLO, D.; BURSZTYN, I. Turismo de Base Comunitária: diversidade de olhares e experiências brasileiras. Rio de Janeiro: Letra e Imagem, 2009.

SCHECHNER, R. Between theater and anthropology. Philadelphia: The University of Pennsylvania Press, 1985.

. Performance theory. New York and London: Routledge, 1988.

TurnER, J. H. A theory of social interaction. Stanford: Stanford University Press, 1988.

UNESCO. Convenção para a Salvaguarda do Patrimônio Cultural Imaterial. Disponível em: 〈http:// portal.iphan.gov.br/uploads/ckfinder/arquivos/ConvencaoSalvaguarda.pdf> Acesso em: 12 set. 2015.

Curso virtual sobre registro e inventario del patrimonio cultural inmaterial. s/n, 2010.

YÁZIGI, E. To be or not to be: sobre o autêntico e o falsificado nas construções do turismo. Cultur Revista de Cultura e Turismo, ano 3, n. 3, Ilhéus: 2009. 